\title{
ESTRATEGIAS PARA DIFERENCIAR Xanthomonas campestris pv. phaseoli CON SALES INORGÁNICAS' ${ }^{1}$
}

\author{
Mildred Zapata², Rosario Gaud ${ }^{2}$
}

\begin{abstract}
RESUMEN
Estrategias para diferenciar Xanthomonas campestris pv. phaseoli con sales inorgánicas. Colonias de Xanthomonas campestris pv. phaseoli (Xcp) aisladas de hojas de habichuelas con síntomas de tizón común en Puerto Rico, República Dominicana y Costa Rica fueron caracterizadas como patogénicas en hojas de Phaseolus vulgaris. Sin embargo, éstas fueron clasificadas en los patovares phaseoli, vesicatoria, carotae y xanthosoma por el sistema Biolog. Las cepas de $X c p$ crecidas en 2, 3, 5-Trifenil cloruro de tetrazolio (TTC) mostraron colonias convexas, brillosas, lisas y de color rojo en diferentes tamaños. TTC fue reducido por las cepas de Xcp a un pigmento rojo intenso, un formazán de trifenilo. No se encontraron diferencias en virulencia y tipos de colonias en las cepas identificadas por pruebas de patogenicidad como Xcp. Por otro lado, hubo diferencias en el tipo de colonia en cultivos bacterianos identificados como: Pseudomonas cissicola, P. fulva, Corynebacterium, Rhodococcus, y Shingomonas.
\end{abstract}

\begin{abstract}
Attempts to differentiate Xanthomonas campestris pv. phaseoli using inorganic salts. Strains of Xanthomonas campestris pv. phaseoli (Xcp) isolated from common blight diseased bean leaves at Puerto Rico, Dominican Republic and Costa Rica were determined as pathogenic on the common bean, Phaseolus vulgaris. The strains determined by pathogenicity tests as pv. phaseoli were differentiated into pathovars such as phaseoli, vesicatoria, carotae, and xanthosoma by the use of the Biolog Identification System. Strains grown in 2, 3, 5-triphenyl tetrazolium chloride (TTC) showed a convex, shiny and smooth red pigment, a triphenyl formazan. No differences in virulence were found in the Xcp strains identified by pathogenicity tests. Two colony types were found in $X$. campestris. Also, colony types differences were found with Pseudomonas cissicola, P. fulva, Corynebacterium, Rhodococcus and Shingomonas.
\end{abstract}

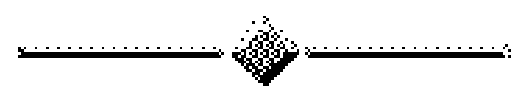

\section{INTRODUCCIÓN}

El género Xanthomonas representa una de las bacterias de mayor importancia epidemiológica en las zonas tropicales. Dentro de este género, la especie campestris tiene gran importancia económica en Puerto Rico porque ataca cultivos comestibles y plantas ornamentales. La clasificación de la especie campestris ha sido motivo de estudios taxonómicos y se ha propuesto cambiar la especie campestris a axonopodis. Por ende, muchos patovares serán cambiados a este último grupo de existir evidencia significativa que sustente el cambio en la clasificación.

En Puerto Rico Xanthomonas campestris se ha identificado causando daños de importancia en el culti- vo del frijol común, Phaseolus vulgaris L. y en la planta ornamental Anthurium andreanum L. con los patovares phaseoli y dieffenbachiae, respectivamente.

Dentro del patovar phaseoli se han informado dos variantes: $X c p(\mathrm{c})=$ tipo común y el $X c p(\mathrm{f})=$ fuscans. El tipo común representa cepas de phaseoli de colonias de pigmentación amarilla, mientras que el tipo fuscans es de color amarillo pero produce otro pigmento melanoide extracelular, el cual es difusible al medio de cultivo. Las enfermedades causadas por estas bacterias son díficiles de distinguir bajo condiciones de campo y el tipo fuscans puede perder la capacidad de perder melanina, lo que haría díficil la diferenciación de ésta del tipo común. Por otro lado, los cambios ambientales afectan la sobrevivencia y viabilidad de las bacterias fi-

\footnotetext{
1 Presentado en la XLVI Reunión Anual del PCCMCA, San Juan, Puerto Rico, 2000.

2 Empresa de Granos Básicos, Estación Experimental Agrícola, Protección de Cultivos. Universidad de Puerto Rico P.O. Box 9030, Mayagüez P.R. 00681-9030. Tel. (787)265-3859, Extensión 3723.//e-mail. M_Zapata@uprm.edu
} 
topatógenas e influyen en la dinámica de las comunidades microbianas. Xanthomonas es una bacteria saprófita facultativa por lo que los cambios ambientales pueden afectar directamente su sobrevivencia y provocar cambios genéticos permanentes. El estrés bajo condiciones de sobrevivencia puede afectar adversamente la viabilidad de las bacterias, lo que ha estimulado la investigación al respecto. Algunos investigadores recomiendan para medir viabilidad el que se use actividad metabólica en vez de crecimiento bacteriano (división o crecimiento de colonias). Roslev y King (1993) encontraron que el tetrazolio se puede usar con éxito como indicador del sistema de transporte de electrones y de viabilidad. Las sales de tetrazolio se han utilizado como aceptores de electrones de hidrógeno para evaluar el efecto de sustancias anticancerosas en células eucariotas (Vistica et al., 1991). Se asume que sólo las células vivas pueden reducir las sales de tetrazolio a derivados de formazan. En adición se ha utilizado la reducción metabólica de sales solubles de tetrazolio a formas insolubles de formazan para localizar enzimas. Thom et al. (1993) determinaron que la adición de glucosa y la permeabilidad de la célula se relacionan a la deposición de formazan.

Debido a lo controversial del tema relacionado a la clasificación de Xanthomonas y a la necesidad de mantener un sistema que ayude al fitopatólogo a identificar con mayor precisión las bacterias fitopatógenas, se estudiaron los parámetros de utilización de sales inorgánicas, azúcares y viabilidad de bacterias asociadas a tejidos enfermos, en especial las del género Xanthomonas. Estos criterios se utilizan para diferenciar entre las especies campestris y axonopodis. Se estudiaron las características de las variantes de Xcp y de las bacterias patógenas y no patógenas en medios suplementados con sales, con el fin de diferenciarlas en medio de cultivo simplificando la selección de bacterias a probar en condiciones de invernadero.

El objetivo de este estudio fue determinar si las variantes de $X c p$ y de otras bacterias asociadas a plantas como patógenas y no patógenas muestran diferencias en medio de crecimiento suplementado con cloruro de tetrazolio, cloruro de sodio y azúcares diferenciales.

\section{MATERIALES Y MÉTODOS}

Se escogieron para el estudio bacterias provenientes de dos géneros de plantas representando un cultivo (P. vulgaris) y una ornamental (A. andreanum) de importancia económica en Puerto Rico atacados por la bacteria Xanthomonas campestris pv. phaseoli $(X c p)$ y dieffenbachiae $(X c d)$, respectivamente.

Estas se coleccionaron de hojas de frijol que mostraban síntomas del tizón común en Costa Rica, México, Honduras, Guatemala, Puerto Rico y República Dominicana mientras que las de anturio se recolectaron en Puerto Rico. Se aislaron e identificaron las bacterias asociadas a los tejidos foliares enfermos de ambos húespedes. Las hojas de frijol mostraban síntomas de la enfermedad conocida como tizón común causado por $X c p$ y las de anturio síntomas parecidos a la bacteriosis causada por $X c d$. Se utilizaron métodos ordinarios de aislamiento e incubación a $28^{\circ} \mathrm{C}$, para la identificación se utilizó el sistema computarizado Biolog. Las colonias se caracterizaron por su pigmentación, bordes, y forma en medio de agar nutritivo a las 72 y 120 horas. Cada aislado fue caracterizado mediante la prueba de $\mathrm{KOH}$ al $3 \%$ antes de realizar el procedimiento de identificación mediante el sistema de Biolog.

La patogenicidad de las bacterias aisladas se determinó bajo condiciones de invernadero en sus respectivos húespedes. En frijol se inoculó la hoja trifoliada en plantas de 21 días de sembradas y en anturio la segunda hoja desarrollada desde el ápice de plantas de cuatro meses de sembradas. Cada bacteria se inoculó por triplicado utilizando presillas planas impregnadas con la bacteria a probar lacerando sin perforar en tres puntos del haz de la hoja. Los testigos se inocularon de igual forma utilizando agar nutritivo. Se tomaron datos de los síntomas a los siete, 14, 21, y 28 días después de la inoculación. De esta manera se diferenciaron los patógenos aislados de los que no lo eran. Se empleó un sistema de riego por goteo para irrigar las plantas.

Se utilizaron 64 cultivos bacterianos aislados según descripción previa para estudiar las características de las colonias que crecieron en medios suplementados con sales inorgánicas. El estudio se realizó en dos etapas con las sales: trifenil cloruro de tetrazolio (TTC) y cloruro de sodio. Se preparó una solución stock de TTC al 5\% y se esterilizó en autoclave por $15 \mathrm{~min}$ a $121^{\circ} \mathrm{C}$ y 15 psi. La solución de TTC fue añadida según la concentración deseada al medio esterilizado que contenía 5,0 $\mathrm{g}$ de peptona, $0,5 \mathrm{~g}$ de caseína hidrolizada, 2,5 $\mathrm{g}$ de glucosa y 8,5g de agar por $500 \mathrm{ml}$ de agua (Kelman, 1954). En la primera fase se estudiaron 64 cultivos bacterianos e incluyó concentraciones de TTC de $0,2,0,4,0,6,0,8$ y $1,0 \%$ y cloruro de sodio al $1,0,2,0$, $3,0,4,0$, y $5,0 \%$. En la segunda fase se seleccionaron 21 cultivos y se le dio más énfasis a los cultivos de Xcp. Esta fase incluyó TTC al 1,0, 1,2, 1,4, y $1,8 \%$ y NaCl al 4,0, 5,0,6,0 y 7,0\%. El cloruro de sodio fue suplementado al medio de agar nutritivo utilizando $2,3 \mathrm{~g}$ de 
agar nutritivo en $100 \mathrm{ml}$ de agua destilada. El control consistió de agar nutritivo vertido en placas Petri de 100 x $15 \mathrm{~mm}$. El crecimiento de las colonias fue estimado en mm por el diámetro de la colonia.

Los aislados se activaron en medio nutritivo contenido en viales de $8 \mathrm{ml}$ y tenían 24 horas al momento de sembrar en los medios suplementados con las sales. Las colonias se midieron a las 48 horas y luego se transfirieron hasta un máximo de tres subcultivos para determinar crecimiento y viabilidad.

El metabolismo de las bacterias que se identificaron como $X$. campestris, se estudió con las azúcares diferenciales: glucosa, manosa, galactosa, celobiosa, fructosa y arabinosa.

\section{RESULTADOS}

Se cultivaron por métodos ordinarios las bacterias de hojas de frijol que mostraban síntomas del tizón común causado por Xcp y de A. andreanum que mostraban síntomas de la bacteriosis causada por $X c d$.
El Biolog funcionó en la identificación de las bacterias de Xcp (tipo común y fuscans) a las 24 horas de incubación pero no antes de ese período. Se identificaron en frijol seis patovares de $X c p$ tipo común: phaseoli, vesicatoria, carotae, aglonema, translucens y oryzae (Cuadro 1). El Xcp tipo fuscans fue identificado dentro de los pvs. phaseoli, vesicatoria, aglonema, carotae y xanthosoma. Todas estas fueron patogénicas en frijol bajo condiciones de invernadero.

Los cultivos de Xcp (común y fuscans) metabolizaron glucosa, manosa, galactosa, cellobiosa, fructosa y variaron en el metabolismo de arabinosa (33\% del tipo común y $25 \%$ del tipo fuscans) (Cuadro 2).

Se encontraron asociadas a hojas enfermas de frijol, las bacterias Curtobacterium, Enterobacter agglomerans, E. cloacae, Pseudomonas fulva, P. cissicola, Corynebacterium jeikeum y Agrobacterium rhizogenes las cuales no resultaron patogénicas (Cuadro 1).

En anturio se identificó el patógeno, Xanthomonas campestris pv. dieffenbachiae, y las no patógenas: Stretizia, Clavibacter, Rhodococcus fascians y Sphingomonas paucimobilisa. Estas no resultaron patogénicas en anturio.

Cuadro 1. Descripción de algunas bacterias utilizadas en la determinación de resistencia a sales inorgánicas en medio de cultivo.

\begin{tabular}{|c|c|c|c|c|}
\hline \multirow[t]{2}{*}{ No. Aislado } & \multicolumn{2}{|c|}{ Identidad 1} & \multicolumn{2}{|c|}{ Origen } \\
\hline & Biolog & Patogenicidad & Localidad & Huésped 2 \\
\hline 872 & X. campestris pv. phaseoli & $X c p$ & República Dominicana & P. vulgaris \\
\hline $878 *$ & $X$. campestris pv. phaseoli & $X c p$ & República Dominicana & P. vulgaris \\
\hline 881 & X. campestris pv. phaseoli & $X c p$ & República Dominicana & P. vulgaris \\
\hline $974 *$ & $X$. campestris pv. phaseoli & $X c p$ & Puerto Rico & P. vulgaris \\
\hline 484 & X. campestris pv. phaseoli & $X c p$ (control) & Puerto Rico & P. vulgaris \\
\hline 940 & $X$. campestris pv. vesicatoria & $X c p$ & Costa Rica & P. vulgaris \\
\hline 983 & $X$. campestris pv. vesicatoria & $X c p(\mathrm{f})$ & Puerto Rico & P. vulgaris \\
\hline 924 & X. campestris pv. aglonema & $X c p$ & Costa Rica & P. vulgaris \\
\hline 985 & $X$. campestris pv. xanthosoma & $X c p(\mathrm{f})$ & Puerto Rico & P. vulgaris \\
\hline $979 *$ & $X$. campestris pv. xanthosoma & $X c p(\mathrm{f})$ & Costa Rica & P. vulgaris \\
\hline $982 *$ & $X$. campestris pv. carotae & $X c p(\mathrm{f})$ & Costa Rica & P. vulgaris \\
\hline $904 *$ & $X$. campestris pv. strelitzia & - & Puerto Rico & A. andreanum \\
\hline 1045 & X. campestris pv. translucens & $X c p$ & México & P. vulgaris \\
\hline 919 & $\mathrm{X}$. oryzae pv. oryzae & $X c p$ & Costa Rica & P. vulgaris \\
\hline 981 & Pseudomonas cissicola & - & Puerto Rico & P. vulgaris \\
\hline 1043 & Pseudomonas fulva & - & México & P. vulgaris \\
\hline 880 & Corynebacterium jeikeum & - & República Dominicana & P. vulgaris \\
\hline 943 & Curtobacterium & - & Costa Rica & P. vulgaris \\
\hline $891 *$ & Rhodococcus fascians & - & Puerto Rico & A. andreanum \\
\hline $888 *$ & Shingomonas paucimobilisa & - & Puerto Rico & A. andreanum \\
\hline $892 *$ & Desconocida & - & Puerto Rico & A. andreanum \\
\hline 1003 & Enterobacter agglomerans & - & Puerto Rico & P. vulgaris \\
\hline 874 & E. cloacae & - & República Dominicana & P. vulgaris \\
\hline 989 & Agrobactrium rhizogenes & - & Puerto Rico & P. vulgaris \\
\hline 933 & $X$. campestris dieffenbachiae & + Aa. & Puerto Rico & A. andreanum \\
\hline 944 & Clavibacter michiganense & - & Puerto Rico & A. andreanum \\
\hline
\end{tabular}

1 Se estableció la identidad de la bacteria con el sistema BIOLOG y pruebas de patogenicidad en $P$. vulgaris y se diferenciaron las variantes de Xcp = Xanthomonas campestris pv. phaseoli tipo común y fuscans.

2 Origen: La especie huésped del cual la bacteria fue aislada 
Cuadro 2. Reacción de Xanthomonas campestris pv. phaseoli (tipo común y fuscans) a metabolitos utilizados en la diferenciación de la especie.

\begin{tabular}{|c|c|c|c|c|c|c|}
\hline Bacteria $^{1}$ G & Glucosa & Arabinosa & Manosa & Galactosa & Cellobiosa & Fructosa \\
\hline \multicolumn{7}{|l|}{$X c p(c)$} \\
\hline 872 & + & $+/-2$ & + & + & + & + \\
\hline 878 & + & - & + & + & + & + \\
\hline 881 & + & - & + & + & + & + \\
\hline 940 & + & - & + & + & + & + \\
\hline 980 & + & - & + & + & + & + \\
\hline 484 & + & $+/-$ & + & + & + & + \\
\hline \multicolumn{7}{|l|}{$X c p(f)$} \\
\hline 982 & + & + & + & + & + & + \\
\hline 983 & + & - & + & + & + & + \\
\hline 985 & + & - & + & + & + & + \\
\hline 979 & + & - & + & + & + & + \\
\hline \multicolumn{7}{|l|}{ Control } \\
\hline X. campestri & ris + & + & + & + & + & + \\
\hline X. axonopod & dis + & - & - & - & - & + \\
\hline
\end{tabular}

1 Bacteria: Xcp (c) = Xanthomonas campestris pv. phaseoli tipo común, $X c p(\mathrm{f})=X . c$. pv. phaseoli tipo fuscans.

$2+=$ reacción positiva, $-=$ reacción negativa, $+/-=$ reacción intermedia, reacción medida a $590 \mathrm{~nm}$.

Se observaron diferencias de los aislados no patógenas de Enterobacter agglomerans versus los aislados patógenas en TTC al 0,2\% (Figura 1). E. agglomerans mostró una produción de fluído acuoso en TTC en concentraciones de $0,2 \%$ y dicha producción acuosa fue observada en medios con concentraciones mayores a diferencia de los patógenos Xcp y Agrobacterium rhizogenes que no mostraron producción de fluido acuoso.

Los aislados patógenos de $X c p$ tipo común en su gran mayoría resistieron de $0,2-1,0 \%$ de TCC mientras que el tipo fuscans mostró mayor sensitividad (Cuadro 3). También se observó que el $40 \%$ de $X c p$ tipo común tolera $3 \%$ de cloruro de sodio mientras que el Xcp tipo fuscans no lo resiste. La colonia de $X c p$ tipo común fue de color rosado claro y brilloso en TTC al $0,2 \%$, y rosado oscuro al 0,4 y $0,8 \%$. Aún cuando hubo crecimiento se redujo significativamente el tamaño de la colonia, especialmente al 0,8 y $1,0 \%$. Se encontró que el $100 \%$ de la población general de $X c p$ fue resistente-tolerante a $\mathrm{NaCl}$ al $2 \%$ y $40 \%$ fue resistente al $3 \%$. No se encontró ningún fuscans que tolerara niveles de $\mathrm{NaCl}$ mayores a $2 \%$.

La bacteria patógena, Agrobacterium rhizogenes mostró colonias rosadas al $2 \%$ y se hizo más intenso el color sin reducción de crecimiento al 0,4\%. Se obser-
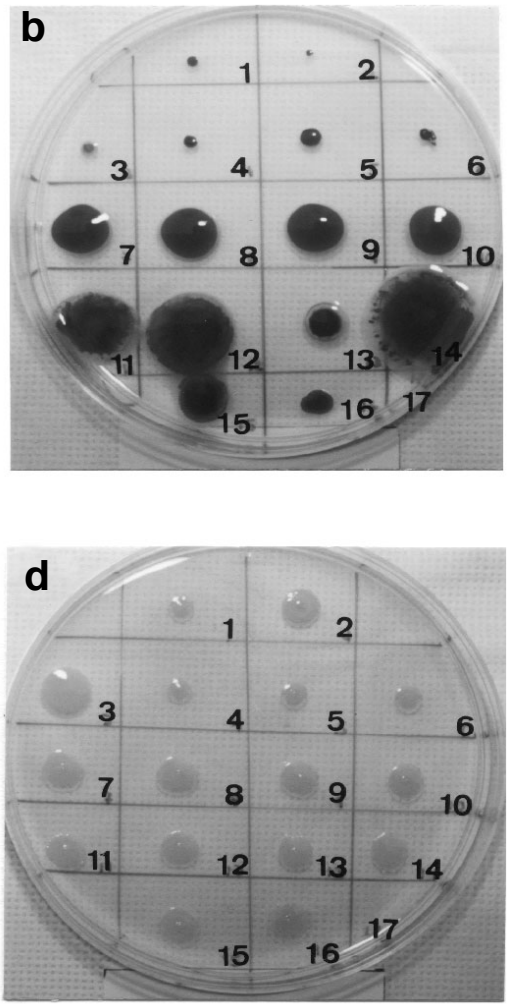

Plato: $a=0,6 \%$ TTC, $b=0,8 \%, c=1,0 \%$ TTC y d=agar nutritivo

Bacterias probadas: 1-6= Diferentes patovares de Xanthomonas campestris; 7-10= Diferentes aislados de Agrobacterium mostrando colonias compactas y elevadas; 11-15= Diferentes aislados de Enterobacter agglomerans mostrando colonias de tipo fluido; 16= Bacteria no identificada y 17= Control, sin bacteria.

Figura 1. Colonias de bacterias crecidas en diferentes concentraciones de TTC. 
Cuadro 3. Crecimiento de Xanthomonas campestris pv. phaseoli (tipo común y fuscans) en medios de cultivo suplementados con sales inorgánicas.

\begin{tabular}{cccccccccccc}
\hline Cepa $^{1}$ & \multicolumn{1}{c}{ Cloruro de Tetrazolio (\%) } & \multicolumn{1}{c}{ Cloruro de Sodio (\%) } \\
& 0,2 & 0,4 & 0,6 & 0,8 & 1,0 & 1 & 2 & 3 & 4 & 5 \\
\hline $\boldsymbol{X} \boldsymbol{c} \boldsymbol{p}(\boldsymbol{c})$ & & & & & & & & & & \\
872 & $\mathrm{R}$ & $\mathrm{R}$ & $\mathrm{R}$ & $\mathrm{R}$ & $\mathrm{R}$ & $\mathrm{R}$ & $\mathrm{R}$ & $\mathrm{S}$ & $\mathrm{S}$ & $\mathrm{S}$ \\
878 & $\mathrm{R}$ & $\mathrm{S}$ & $\mathrm{S}$ & $\mathrm{S}$ & $\mathrm{S}$ & $\mathrm{R}$ & $\mathrm{R}$ & $\mathrm{R}$ & $\mathrm{S}$ & $\mathrm{S}$ \\
881 & $\mathrm{R}$ & $\mathrm{R}$ & $\mathrm{R}$ & $\mathrm{R}$ & $\mathrm{R}$ & $\mathrm{R}$ & $\mathrm{R}$ & $\mathrm{R}$ & $\mathrm{S}$ & $\mathrm{S}$ \\
940 & $\mathrm{R}$ & $\mathrm{R}$ & $\mathrm{R}$ & $\mathrm{R}$ & $\mathrm{R}$ & $\mathrm{R}$ & $\mathrm{R}$ & $\mathrm{S}$ & $\mathrm{S}$ & $\mathrm{S}$ \\
982 & $\mathrm{R}$ & $\mathrm{R}$ & $\mathrm{S}$ & $\mathrm{S}$ & $\mathrm{S}$ & $\mathrm{R}$ & $\mathrm{R}$ & $\mathrm{S}$ & $\mathrm{S}$ & $\mathrm{S}$ \\
$\% \mathrm{Res}^{2}$ & 100 & 80 & 60 & 60 & 60 & 100 & 100 & 40 & 0 & 0 \\
$\boldsymbol{X} \boldsymbol{c} \boldsymbol{p}(\boldsymbol{f})$ & & & & & & & & & & \\
982 & $\mathrm{R}$ & $\mathrm{S}$ & $\mathrm{S}$ & $\mathrm{S}$ & $\mathrm{S}$ & $\mathrm{R}$ & $\mathrm{R}$ & $\mathrm{S}$ & $\mathrm{S}$ & $\mathrm{S}$ \\
983 & $\mathrm{R}$ & $\mathrm{R}$ & $\mathrm{R}$ & $\mathrm{R}$ & $\mathrm{R}$ & $\mathrm{R}$ & $\mathrm{R}$ & $\mathrm{S}$ & $\mathrm{S}$ & $\mathrm{S}$ \\
985 & $\mathrm{R}$ & $\mathrm{R}$ & $\mathrm{R}$ & $\mathrm{R}$ & $\mathrm{R}$ & $\mathrm{R}$ & $\mathrm{R}$ & $\mathrm{S}$ & $\mathrm{S}$ & $\mathrm{S}$ \\
979 & $\mathrm{R}$ & $\mathrm{S}$ & $\mathrm{S}$ & $\mathrm{S}$ & $\mathrm{S}$ & $\mathrm{R}$ & $\mathrm{R}$ & $\mathrm{S}$ & $\mathrm{S}$ & $\mathrm{S}$ \\
$\%$ Res. & 100 & 50 & 50 & 50 & 50 & 100 & 100 & 0 & 0 & 0 \\
\hline
\end{tabular}

1 Cepa: $X c p(c)=$ Xanthomonas campestris pv. phaseoli tipo común, $X c p(f)=$ Xanthomonas campestris pv. phaseoli ( tipo fuscans).

$2 \%$ Res. = Porcentaje de cepas con resistencia a las concentraciones indicadas.

$3 \mathrm{R}=$ resistente, crece en medio suplementado con sales y $\mathrm{S}=$ sensitivo, no crece en medio suplementado con sales.

vó crecimiento también al 0,8\%. La bacteria no patógena, Enterobacter agglomerans mostró una zona rosada clara pequeña al 0,2 \% con una amplia zona acuosa de color claro. Esta bacteria forma colonias de color rosa intenso al $0,4 \%$ y $0,8 \%$ pero mantiene zonas fluidas de tipo acuoso claras alrededor de la colonia, las cuales se pueden regar fácilmente en el medio de cultivo.

El tamaño de las colonias de $X c p$ varió de 0,2 a 6,9 mm cuando se analizó el crecimiento general en todos los tratamientos con sales inorgánicas (Cuadro 4). Esto permite diferenciar cerca de cuatro grupos de tamaños para $X c p$ crecida en sales. El aislado de México identificado como $X c$ pv. translucens fue el que mostró el mayor crecimiento de colonia.

Cuadro 4. Tamaño de bacterias de Xanthomonas campestris pv. phaseoli crecidas en TTC, $\mathrm{NaCl}$ y agar nutritivo ${ }^{1}$.

\begin{tabular}{lrllc}
\hline \multicolumn{1}{c}{ Xc.pv ${ }^{2}$} & No. & Origen & Tamaño & Grupo \\
\hline translucens & 1045 & México & $6,96 \mathrm{a}$ & 1 \\
phaseoli & 872 & Rep. Dom. & $2,96 \mathrm{~d}$ & 2 \\
phaseoli & 940 & Costa Rica & $2,37 \mathrm{ef}$ & 2 \\
oryzae & 919 & Costa Rica & $2,00 \mathrm{f}$ & 2 \\
phaseoli & 974 & Costa Rica & $0,74 \mathrm{fhi}$ & 3 \\
carotae & 982 & Costa Rica & $0,44 \mathrm{ijk}$ & 3 \\
xanthosoma & 979 & Costa Rica & $0,40 \mathrm{jk}$ & 3 \\
phaseoli & 878 & Rep. Dom. & $0,40 \mathrm{jk}$ & 3 \\
phaseoli & 484 & Puerto Rico & $0,25 \mathrm{k}$ & 4 \\
\hline
\end{tabular}

1 Se define Xanthomonas campestris pv. phaseoli de acuerdo a pruebas de patogenicidad en $P$. vulgaris.

${ }^{2} X c \cdot p v=$ Se refiere a la identificación de patovares según el sistema Biolog utilizando las cepas previamente determinadas como $X c$ pv. phaseoli de acuerdo a la prueba de patogenicidad.
El Xcp tipo fuscans, bacteria patógena equivalente(según el sistema Biolog) a Xanthomonas campestris pvs. vesicatoria, carotae, aglonema y xanthosoma fue sensitiva y no creció en 1,0\% de TTC (Cuadro 5). En cambio los pvs. translucens y stretizia crecieron en 1,8 $\%$ y $1,4 \%$, respectivamente. La colonia del pv. translucens se caracteriza por desarrollar un centro rosado oscuro el cual es rodeado por un halo más claro de color naranja. El $60 \%$ del pv. phaseoli fue resistente al $1,0 \%$ y el $40 \%$ de los aislados resistió $1,8 \%$ de TTC. Pseudomonas fulva toleró $1,8 \%$ de TTC. La colonia tuvo pigmento y formó un centro rosado rodeado de una área naranja. Clavibacter creció en 1,8\% de TTC en un $50 \%$ de su población. Enterobacter cloacae, Shingomonas, y Curtobacterium no crecieron en 1,0\% de TTC. Corynebacterium creció en $1 \%$ de TTC (Cuadro 5).

Cuadro 5. Crecimiento de bacterias asociadas con tejidos enfermos en medio de cultivo suplementado con TTC.

\begin{tabular}{|c|c|c|c|c|}
\hline \multirow[b]{2}{*}{ Bacteria } & \multicolumn{4}{|c|}{ TTC 1} \\
\hline & 1,0 & 1,2 & 1,4 & 1,8 \\
\hline Xanthomonas campestris pv: & $60 \%+2$ & $40 \%+$ & $40 \%+$ & $40 \%+$ \\
\hline phaseoli & $40 \%-$ & $60 \%-$ & $60 \%-$ & $60 \%-$ \\
\hline vesicatoria & - & - & - & - \\
\hline carotae & - & - & - & - \\
\hline stretizia & + & + & + & - \\
\hline aglonema & - & - & _- & - \\
\hline translucens & + & + & + & + \\
\hline Pseudomonas fulva & + & + & + & + \\
\hline Enterobacter cloacae & - & - & - & - \\
\hline Sphingomonas & - & - & - & - \\
\hline \multirow[t]{2}{*}{ Clavibacter } & $50 \%+$ & $50 \%+$ & $50 \%+$ & $50 \%+$ \\
\hline & $50 \%-$ & $50 \%-$ & $50 \%-$ & $50 \%-$ \\
\hline Curtobacterium & - & - & - & - \\
\hline Corynebacterium & + & - & - & - \\
\hline
\end{tabular}

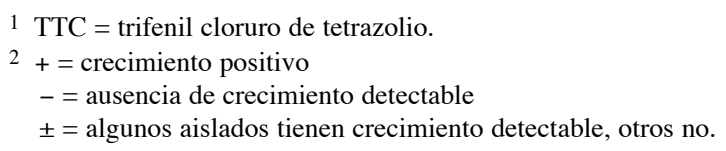

Al comparar la población general de $X c p$ tipo común y fuscans se encontró que el $53 \%$ de la población toleró $1 \%$ de TTC y esto declinó a $38 \%$ de la población cuando se usó TTC al 1,2-1,8 \% (Cuadro 6). De ésto 55-44\% de la población del tipo común mostró resistencia al TTC de 1,0-1,8 \% mientras que el tipo fuscans varió de 50-25\% con TTC de 1,0-1,8\% indicando mayor sensitividad al medio.

Xanthomonas campestris pvs. phaseoli, vesicatoria, carotae, stretizia, aglonema y translucens y Enterobacter cloacae, Sphingomonas y Corynebacterium fueron sensitivos y no crecieron en $4 \%$ de $\mathrm{NaCl}$ (Cuadro 7). Clavibacter, Pseudomonas fulva y Curtobacterium crecieron en 5 y $6 \%$ de $\mathrm{NaCl}$, respectivamente. 
Cuadro 6. Porcentaje de la población de Xanthomonas campestris pv. phaseoli que creció en medios suplementados con sales inorgánicas

\begin{tabular}{lccccrrrrr}
\hline \multicolumn{1}{c}{ Bacteria } & \multicolumn{3}{c}{ TTC } & \multicolumn{5}{c}{ NaCl } \\
& $\mathbf{1 , 0}$ & $\mathbf{1 , 2}$ & $\mathbf{1 , 4}$ & $\mathbf{1 , 8}$ & $\mathbf{4}$ & $\mathbf{5}$ & $\mathbf{6}$ & $\mathbf{7}$ \\
\hline Resistente - Tolerante $^{2}$ & & & & & & & & \\
Xcp general & 53 & 38 & 38 & 37 & 15 & 15 & 15 & 15 \\
tipo común & 55 & 44 & 44 & 44 & 22 & 22 & 22 & 22 \\
tipo fuscans & 50 & 25 & 25 & 25 & 0 & 0 & 0 & 0 \\
Sensitivo & & & & & & & & \\
Xcp general & 46 & 61 & 61 & 61 & 85 & 85 & 85 & 85 \\
tipo común & 46 & 56 & 56 & 56 & 78 & 78 & 78 & 78 \\
tipo fuscans & 50 & 75 & 75 & 75 & 100 & 100 & 100 & 100 \\
\hline
\end{tabular}

1 Incluye todas las $X c p$ identificadas por pruebas de patogenicidad en $P$. vulgaris.

2 Respuestas Resistente-Tolerante - Incluye todas las cepas resistentes o capaces de crecer en medios suplementados más aquellas que toleran o crecen con dificultad.

Thom et al. (1993), observaron que diferentes especies de bacteria reducen el tetrazolio en forma diferente. Por otro lado, el análisis de la actividad respiratoria es una de las herramientas más usadas en el estudio fisiológico de las bacterias presentes en agua de lagos (Dufour y Colón, 1992; Rodríguez et al., 1992 y Gasol et al., 1995. Zimmerman et al. (1978) estudiaron la actividad respiratoria in situ de cloruro de feniltetrazolio al compuesto insoluble de cristales de formazan. Dufour y Colón (1992) modificaron el método descrito por Zimmerman et al. (1978) para detectar células activas versus inactivas en ambientes acuáticos. Posh et al. (1997) hicieron estudios donde midieron las dimensiones de la célula y los cristales de formazan como indicadores de actividad metábolica de una célula.

$X c p$ y $X c p f$ son difíciles de diferenciar bajo condiciones de cultivo, especialmente cuando el tipo fuscans pierde la capacidad para producir melanina. Las dife-

Cuadro 7. Crecimiento de bacterias asociadas con hojas enfermas en medio de cultivo suplementado con cloruro de sodio

\begin{tabular}{lllll}
\hline \multicolumn{1}{c}{ Bacteria } & \multicolumn{5}{c}{ Cloruro de Sodio (\%) } \\
\hline Xanthomonas campestris pv: & 4 & 5 & 6 & 7 \\
phaseoli & - & - & - & - \\
vesicatoria & - & - & - & - \\
carotae & - & - & - & - \\
stretizia & - & - & - & - \\
aglonema & - & - & - & - \\
Pseudomonas fulva & - & - & - & - \\
Enterobacter cloacae & + & + & + & + \\
Sphingomonas & - & - & - & - \\
Clavibacter & - & - & - & - \\
Curtobacterium & + & + & \pm & - \\
Corynebacterium & + & + & + & \pm \\
\hline
\end{tabular}

+ crecimiento

- no crecimiento

\pm algunos aislados crecen, otros no tienen crecimiento detectable. rencias detectadas bajo condiciones in vitro indican la presencia de biotipos con resistencia a TTC y $\mathrm{NaCl}$. En ambos grupos se detectó diversidad en la actividad metabólica. Se evaluará la capacidad de reducir tetrazolio en medio líquido con espectrofotometría, para cuantificar la capacidad metabólica entre las bacterias con fines de diferenciación dentro de los biotipos determinados en este estudio.

\section{CONCLUSIONES}

Hubo diferencias fenotípicas entre bacterias patógenas y no patógenas aisladas de los tejidos enfermos. La diferencia consistió en que las bacterias no patógenas asociadas a los húespedes de frijol y anturio, produjeron un fluido acuoso de pigmentación clara en medio de TTC, mientras que las bacterias virulentas desarrollaron colonias de color rosado oscura y definidas sin fluido. Este resultado contrasta con lo informado por Kelman (1954) para Pseudomonas solanacearum donde el tipo virulento produce colonias con centros rojos y fluido y las no virulentas desarrollaban colonias rosadas oscuras sin fluido. Dicho medio se usa actualmente para diferenciar colonias virulentas y no virulentas de $P$. solanacearum. TTC resultó efectivo en distinguir biotipos de Xcp. Esta sal se usa para diferenciar biotipos de Agrobacterium tumefaciens biovar 3 (Heskett, 1970; Kado y Heskett, 1970; Roy y Sasser, 1983) y para diferenciar X. campestris pv manihotis (Athayda, 1983).

El tetrazolio se ha utilizado para cuantificar la capacidad reductora de las células vivas procariotas y eucariotas. Estas sales aceptan electrones de sustratos oxidados que resultan en la formación de formazan. Vistica et al. (1991) encontraron que el transporte y el metabolismo de glucosa son requeridos para una máxima reducción de la sal. El cloruro de trifeniltetrazolio fue incorporado y reducido por ciertas especies de bacterias y ésto causó que el compuesto se tornara rojo y las colonias se vieran rojo o rosado. Aquellas bacterias que muestran esta actividad indican la presencia de una deshidrogenasa.

Se ha propuesto que el grupo de $X c p$ sea reconocido dentro del grupo axonopodis. Los resultados sostienen que $X c p$ tiene mayor relación al grupo campestris que a axonopodis en cuanto al metabolismo de los azúcares diferenciales y tolerancia a $\mathrm{NaCl}$, criterios que son utilizados para diferenciar la especie dentro del género Xanthomonas. El grupo campestris tolera 2,5-5\% de $\mathrm{NaCl}$ mientras que axonopodis tolera 1\% (Bergey's manual..., 1975). Se confirmó que las Xanthomonas aisladas de $P$. vulgaris y de A. andreanum muestran ma- 
yor relación a la especie campestris que a axonopodis. Se pudo diferenciar biotipos de $X$. campestris pv. phaseoli de acuerdo a la utilización de TTC y diferencias en tamaño de la colonia. Xcp tipo común mostró mayor viabilidad y resistencia a las sales que el fuscans.

El medio TTC fue efectivo para diferenciar grupos de colonias dentro del patovar phaseoli. Este medio se utiliza para diferenciar otras bacterias tales como: E. coli (Lederberg, 1948), P. solanacearum (Kelman, 1954) y (Hayward, 1960) y E. carotovora (Logan, 1966).

\section{LITERATURA CITADA}

ATHAYDA, J.T. 1983. Use of tetrazolium to detect virulence in Xanthomonas campestris pv. manihotis. Fitopatología Brasiliera 8 (2): 283-290.

BERRIDGE, M.V.; TAN, A; MCCOY, K.D.; WANG, R. 1996. The biochemical and cellular basis of cell proliferation assays that use tetrazolium salts. Biochemica 4: 14-19.

BERGEY'S MANUAL OF DETERMINATIVE BACTERIOLOGY. 1975. Eigth edition. William y Wilkins. p. 245.

DUFOUR, P.; COLÓN, M. 1992. The tetrazolium reduction method for assessing the viability of individual bacterial cells in aquatic environments: improvements, performance and applications. Hydrobiologia 232:211-218.

GASOL, J.M.; DEL GIORGIO, P.A.; MASSANA, R.; DUARTE, C.M. 1995. Active versus inactive bacteria: size-dependent in a coastal marine plankton community. Mar. Ecol. Prog.Ser. 128:91-97.

HAYWARD, A.C. 1960. A method of characterizing Pseudomonas solanacearum. Nature 186: 405-406.

HESKETT, M.G. 1970. Selective media for isolation of Agrobacterium solanacearum. Nature 186:405-406.

KADO,C.I.; HESKETT, M.G. 1970. Selective media for isolation of Agrobacterium, Corynebacterium, Erwinia, Pseudomonas and Xanthomonas. Phytopathology 60:969-976.

KELMAN, A. 1954. The relationship of pathogenicity in Pseudomonas solanacearum to colony appearance on a tetrazolium medium. Phytopathology 44: 693 695 .

LEDERBERG, J. 1948. Detection of fermentative variants with tetrazolium. J. Bacteriology 56:695.

LOGAN, C. 1966. Simple method of differentiating Erwinia carotovora and E. atroseptica 'aroidae'. Nature 212:1584-1585.

POSH, T.; PERNTHALER, A.; ALFREIDER, A.; PSENNER, R. 1997. Cell-specific respiratory activity of aquatic bacteria studied with the tetrazolium reduction method, cyto-clear slides, and image analysis. Applied and Environmental Microbiology 63: 867-873.

RODRÍGUEZ, G. G.; PHIPPS, D.; ISHIGURO, K.; RIDGWAY, H.F. 1992. Use of a fluorescence redox probe for direct visualization of actively respiring bacteria. Appl. Environ. Microbiol. 58: 1801-1808.

ROSLEV, P.; KING, G.M. 1993. Application of a tetrazolium salt with a water-soluble formazan as an indicator of viability in respiring bacteria. Applied and Environmental Microbiology 59: 2891-2896.

ROY, M.A.; SASSER, M. 1983. A medium selective for Agrobacterium tumefaciens biotype 3 (abstract). Phytopathology 73:810.

SCUDIERO D.A.;SHOEMAKER， R.H.; PAULL，K.D; MONKS, A.; TIERNEY, S.; NOFZIGER T.H.; CURRENNS, M.J.; SENNIFF, D.; BOYD, M.R. 1988. Evaluation of a soluble tetrazolium/formazan assay for cell growth and drug sensitivity in culture using human and other tumor cell lines. Cancer Research 48: 4827- 4833.

THOM, S.M.; HOROBIN, R.W.; SEIDLER, D., BARER, M.R. 1993. Factors affecting the selection and use of tetrazolium salts as cytochemical indicators of microbial viability and activity. J. Appl. Bacteriol. 74:433-443.

VISTICA, D.T.; SKEHAN, P.; SCUDIERO, D.; MONKS, A.; PITTMAN, A.; BOYD, M.R. 1991. Tetrazolium-based Assays for cellular viability: A critical examination of selected parameters affecting formazan production. Cancer Research 51: 2515-2520.

ZIMMERMANN, R.; ITURRIAGA, R.; BECKER-FIRCK, J. 1978. Simultaneous determination of the total number of aquatic bacteria and the number thereof involved in respiration. Appl. Envirron. Microbiol. 36:926-935. 